\title{
Postmenopozal Osteoporozlu Hastalarda Patolojik Kırık Oluşumu Öngörülebilir mi?
}

\author{
Uğur ERTEM, Jale İRDESEL
}

Bursa Uludağ Üniversitesi Tıp Fakültesi, Fiziksel Tıp ve Rehabilitasyon Anabilim Dalı, Bursa.

\section{ÖZET}

Osteoporoz (OP), kemik kütlesinde azalma ve kemik kırılganlığında artıs ile karakterize metabolik bir kemik hastalığıdır. OP’nin en önemli morbidite ve mortalite nedeni osteoporotik kırık oluşumudur. Postmenopozal osteoporozda (PMO) kırık risk faktörlerini tanımlamak amacıyla yapılan birçok çalışma bulunmasına rağmen, bu çalışmalarda kırık oluşumunda gerçekte hangi risk faktörünün ne kadar etkili olduğu konusundaki bilgiler halen çelişkilidir. Bu çalışmada amaç, PMO'lu hastalarda kırık riskinin öngörülüp öngörülemeyeceğini belirlemektir. Fiziksel Tıp ve Rehabilitasyon Polikliniği'ne başvuran PMO tanılı 124 hasta çalışmaya dahil edildi. Bu hastaların kırık varlığı ve kırığa neden olabilecek risk faktörleri geriye yönelik olarak tarandı. Hastalar kırık varlığına göre, kırığı olan ve olmayan PMO’lu hastalar olarak iki gruba ayrılarak karșılaștıııldı. PMO'lu hastaların 50'sinde (\%40,3) osteoporotik kırık saptanırken, 74 hastada (\%59,7) kırık saptanmadı. İki grup arasında yapılan karşılaştırma sonucunda ileri yaş ile kırık oluşumu arasında istatistiksel olarak anlamlı ilişki saptandı. Vücut kitle indeksi (VKI), menopoz yaşı, 25(OH) D vitamini düzeyleri, dual-enerji X-ışını absorbsiyometri (DEXA) ile değerlendirilen kemik mineral yoğunluğu (KMY) ölçümü T skorları ile kırık oluşumu arasında anlamlı ilişki saptanmadı. Sonuçlar kırık oluşumunun tam olarak öngörülmesinin zor olduğunu düșündürmekle birlikte, daha fazla sayıda veri ile yapılacak daha geniş hasta popülasyonunun tarandığı çalışmalara ihtiyaç olduğunu düşündürmektedir.

Anahtar Kelimeler: Postmenopozal osteoporoz. Kemik mineral yoğunluğu. Patolojik kırık.

Is Pathological Fracture Predictable in Patients with Postmenopausal Osteoporosis?

\begin{abstract}
Osteoporosis (OP) is a metabolic bone disease characterized by a decrease in bone mass and an increase in bone fragility. The most important cause of morbidity and mortality of OP is osteoporotic fracture formation. Although there are many studies carried out to define fracture risk factors in postmenopausal osteoporosis (PMO), there is still controversy in these studies about which risk factor is actually effective in fracture formation. The aim of this study is to determine whether fracture risk can be predicted in patients with PMO. 124 patients diagnosed with PMO who admitted to the Physical Medicine and Rehabilitation outpatient department were included in the study. The presence of fractures and risk factors that may cause fractures in these patients were screened retrospectively. The patients were divided into two groups according to the presence of fractures, as patients with PMO with and without fractures and compared. While osteoporotic fractures were found in 50 of the patients with PMO (40,3\%), no fractures were found in 74 patients $(59,7 \%)$. As a result of the comparison between the two groups, a statistically significant relationship was found between advanced age and fracture formation. There was no significant relationship between body mass index (BMI), age at menopause, vitamin $25(\mathrm{OH}) \mathrm{D}$ levels, bone mineral density (BMD) measurement $\mathrm{T}$ scores evaluated by dual-energy X-ray absorptiometry (DEXA) and fracture formation. Although the results suggest that it is difficult to accurately predict fracture formation, they suggest that studies that will screen a larger patient population with more data are needed.
\end{abstract}

Key Words: Postmenopausal osteoporosis. Bone mineral density. Pathological fracture.

Geliş Tarihi: 23.Şubat.2021

Kabul Tarihi: 17.Mart.2021

\section{Dr. Uğur ERTEM}

Bursa Uludağ Üniversitesi Tıp Fakültesi,

Fiziksel Tıp ve Rehabilitasyon Anabilim Dalı,

Bursa

Tel: 05556007054

E-posta: ugurertem@uludag.edu.tr

Yazarların ORCID ID Bilgisi:

Uğur ERTEM: 0000-0003-2142-2264

Jale IRDESEL: 0000-0002-1456-9121
Osteoporoz (OP), kemik kütlesinde azalma ve kemik kırılganlığında artış ile seyreden metabolik bir kemik hastalığıdır ${ }^{1}$. OP, günümüzde beklenen yaşam süresinin uzaması ile birlikte en önemli sağlık sorunlarından biri haline gelmiştir. Temel sorun, OP'ye bağlı artmış kırık riskidir. OP'ye bağlı oluşan bu kırıklar önemli oranlarda mortalite ve morbidite nedenidir. Kalça ve vertebra kırıkları mortalite ve morbitideyle ilişkisi daha belirgin olan kırıklardır ancak ön kol, humerus, pelvis, tibia, fibula ve kosta kırıkları da oluşabilmektedir ${ }^{2}$. OP'nin önlenebilir ve tedavi edilebilir bir hastalık olduğunu düşünülürse, bu konunun toplum sağlığ 1 


\section{U. Ertem ve J. İrdesel}

açısından ne kadar önemli olduğu daha çok ortaya çıkar.

OP'de kemik yıkımının artması ve kemik yapımının yaşa bağlı olarak azalması sonucu, denge durumunda olan yapım-yıkım döngüsü yıkım lehine bozulur ve kemik kütlesinde azalma meydana gelmeye başlar. Özellikle kadınlarda postmenopozal dönemde, ilk yıllarda azalan östrojen düzeylerine paralel olarak kemik kütlesindeki azalma daha fazladır ${ }^{3}$. Bu açıdan bakacak olursak postmenopozal osteoporoz (PMO) kırık riskinde artışa yol açan sinsi bir hastalıktır ${ }^{4}$.

Literatürde OP tanısının konulması ve kırık riskinin belirlenmesinde, risk faktörlerinin araştırılıp bunların varlığında dual-enerji X-ışını absorbsiyometri (DEXA) ile kemik mineral yoğunluğunun (KMY) değerlendirilmesi yöntemi yaygın olarak kabul görmüştür ${ }^{5}$.

Hastalarda OP'ye bağlı kırık riskinin belirlenmesi ve gerekli önlemlerin alınması çok önemli bir konudur. KMY'den bağımsız olarak daha önce saptanmış bir vertebral kırık varlığı yeni vertebral kırık gelişme riskinde 4-5 kat artışa yol açmaktadır ${ }^{6}$. Ayrıca doğru tedavi ile kırık riskinde ortaya çıkan azalma, daha şiddetli OP bulunan hastalarda daha fazladir ${ }^{7}$. Bu yüzden bu hastaların tanınması olası bir kırık gelişimini önlemede çok daha yararlı olacaktır.

Yapılan bir çalışmada; hormon replasman tedavisi, yaş, vücut kitle indeksi (VKI), sigara, alkol kullanımı, ebeveynde OP öyküsü, romatoid artrit, kardiyovasküler hastalık, tip 2 diyabet, astım, trisiklik antidepresan kullanımı, kortikosteroid kullanımı, düşme öyküsü, menopoz yaşı, kronik karaciğer hastalı̆̆ tinal malabsorpsiyon ve diğer endokrin bozukluklar kadınlarda osteoporotik kırık riski ile anlamlı ve bağımsız olarak ilişkili bulunmuştur ${ }^{8}$. Bu çalışmada, kalça kırığı için Q Kırık Skoru (QFractureScore) değerlendirmesi, ülkemizde de kırık risk değerlendirmesi için kullanılan Kırık Riski Değerlendirme Aracı (FRAX) algoritmasına kıyasla daha etkili bulunmuştur $^{8}$. Başka bir çalışmada Kronik Obstruktif Akciğer Hastalığı (KOAH) olan hastalarda, FRAX skoru ile vertebra kırıklarının prevalansı arasında bir korelasyon bulunmamıştır ve bundan yola çıkarak tek başına ne KMY'nin ne de FRAX skorunun KOAH hastalarında vertebra kırıklarının varlığını tahmin edemeyeceği belirtilmiştir ${ }^{9}$. Otoimmün hastalıklarda FRAX skorunun osteoporotik kırıkları öngörmede uygulanabilirliğinin araştırıldığı bir çalışmada, FRAX skorunun romatoid artrit hastalarında kırık olasılığını doğru bir şekilde öngördüğü ama primer Sjögren ve sistemik lupus eritamatozuslu hastalarda kırık riskini tahmin etmede yetersiz olduğu bildirilmiştir ${ }^{10}$. Başka bir çalışmada, 50-64 yaş arası PMO'lu kadınlarda, FRAX ve Garvan kırık riski değerlendirme aracının 10 yıllık takip süresince kırık yaşayan ve yaşamayan kadınları ayırt edemediği belirtilmiştır ${ }^{11}$. Bu çalışmalardan yola çıkarak, kırık risk değerlendirme algoritma ve ölçekle- rinin kırık riskini öngörmede tam anlamıyla güvenilir bir belirteç olamayacağ 1 düşünülebilir.

OP'de kırık risk faktörlerini tanımlamak amacıyla yapılan birçok çalışma bulunmasına rağmen, bu hastalarda kırık oluşumunda gerçekte hangi risk faktörünün ne kadar etkili olduğu konusundaki bilgiler halen çelişkilidir. Biz de çalışmamızda PMO tanısı alan hastaları inceleyip, frajilite kırığı olan hastalarda kırık oluşumuna neden olabilecek risk faktörlerini belirlemeyi ve bu hastalarda kırık oluşumunun öngörülüp öngörülemeyeceğini belirlemeyi amaçladık.

\section{Gereç ve Yöntem}

Çalışma Bursa Uludağ Üniversitesi Tıp Fakültesi Hastanesi Fiziksel Tıp ve Rehabilitasyon bölümünde retrospektif ve kesitsel olarak gerçekleştirildi. Bu kapsamda 1 Ocak 2020-31 Aralık 2020 tarihleri arasında polikliniğe kayıtlı OP tanısı olan 262 hastanın medikal kayıtları retrospektif olarak incelendi. Tüm hastalara çekilen DEXA femur total, femur boyun ve/veya lomber total vertebra KMY ölçümlerinde Tskorunun $\leq-2,5$ standart sapma (SS) olması durumu OP tanısı olarak kabul edildi. PMO'lu hastalar tespit edildi ve bu hastalardan kırık bulunan hastalar Grup 1, kırık bulunmayan hastalar Grup 2'ye alındı. Bu hastaların kırık varlığı ve kırıkla ilişkisi olabileceğini düşündüğümüz risk faktörleri; yaş, $25(\mathrm{OH})$ Vitamin D düzeyleri, KMY değerleri, VKİ, menopoz yaşları, sigara kullanımı, alkol kullanımı ve annede kalça kırığı öyküsü geriye yönelik olarak tarandı. Premenopozal dönemde olanlar, sekonder ya da ilaca bağlı OP tanısı olanlar ve PMO tanısı olmasına rağmen hastane veri tabanında sonuçlarına ulaşılamayan hastalar istatistiksel analize alınmadı. Çalışma Uludağ Üniversitesi Tıp Fakültesi Klinik Araştırmalar Etik Kurul onayı alınarak (karar no: 2021-2/19, tarih: 20/01/2021) Helsinki Deklarasyonu İlkeleri uyarınca gerçekleştirildi.

\section{Biyoistatistiksel Analiz}

Çalışmanın analizleri SPSS (IBM Corp. Released 2012. IBM SPSS Statistics for Windows, Version 21.0. Armonk, NY: IBM Corp.) istatistiksel analiz programı kullanılarak yapılmıştır. Sürekli değişkenlerin normal dağılıma uygunluğu Shapiro Wilk testi ile incelenmiştir. Test sonucuna göre gruplar arası karşılaştırmalarda bağımsız gruplar testi, Pearson Ki-kare testi, student $\mathrm{t}$ testi ve Mann Whitney U testi kullanılmıştır. Sürekli değer alan değişkenler ortalama, standart sapma, medyan, min.-max. değerleri ile birlikte verilmiştir. Çalışmada istatistiksel anlamlılık $\mathrm{p}<0,05$ olarak kabul edilmiştir. 


\section{Bulgular}

Çalışmaya 262 OP tanılı hasta dahil edildi. Hastane veri tabanında sonuçları eksik olan ve sekonder ya da ilaca bağlı OP tanısı olan 138 hasta istatistiksel analize alınmadı. Çalışma analizleri böylece 124 PMO'lu hasta üzerinden gerçekleştirildi. PMO'lu hastaların 50'sinde $(\% 40,3)$ osteoporotik kırık saptanırken, 74 hastada $(\% 59,7)$ kırık saptanmadı (Şekil 1). İki grup arasında yapılan karşılaştırma sonucunda ileri yaş ile kırık oluşumu arasında istatistiksel olarak anlamlı ilişki saptandı $(\mathrm{p}<0,001)$. VKİ, menopoz yaşı, 25(OH) $\mathrm{D}$ vitamini düzeyleri, DEXA ile değerlendirilen KMY ölçümü T skorları ile kırık oluşumu arasında anlamlı ilişki saptanmadı ( $p>0,05)$ (Tablo I). İki grup arasında hastaların sigara ve alkol kullanımına göre ve annede kalça kırığı olup olmamasına göre dağılımı Tablo II'de, grup 1'deki hastaların kırık bulunan bölgelere göre dağılımı Tablo III'de gösterilmiştir.

Tablo I. Risk faktörleri ile postmenopozal osteoporotik kırık arasındaki ilişki

\begin{tabular}{|c|c|c|c|}
\hline & $\begin{array}{c}\text { Grup } 1 \\
\text { (kırıklı PMO) }\end{array}$ & $\begin{array}{c}\text { Grup 2 } \\
\text { (kırıksız PMO) }\end{array}$ & $\begin{array}{c}P \\
\text { değeri }\end{array}$ \\
\hline $\begin{array}{l}\text { Yaş (ortala- } \\
\text { ma } \pm \text { standart sapma) }\end{array}$ & $69,74 \pm 8,61$ & $62,64 \pm 8,29$ & $<0,001$ \\
\hline $\begin{array}{l}\text { VKi (ortala- } \\
\text { ma } \pm \text { standart sapma) }\end{array}$ & $26,39 \pm 5,16$ & $26,33 \pm 4,28$ & 0,94 \\
\hline $\begin{array}{l}\text { Lomber total T skoru } \\
\text { (medyan (min/max)) }\end{array}$ & $\begin{array}{l}-2,65 \\
(-4,50 /-1,40)\end{array}$ & $\begin{array}{l}-2,80 \\
(-4,60 /-0,90)\end{array}$ & 0,24 \\
\hline $\begin{array}{l}\text { Femur boyun T skoru } \\
\text { (ortalama } \pm \text { standart } \\
\text { sapma) }\end{array}$ & $-2,18 \pm 0,61$ & $-2,12 \pm 0,71$ & 0,59 \\
\hline $\begin{array}{l}\text { Femur total T skoru } \\
\text { (ortalama } \text { standart } \\
\text { sapma) }\end{array}$ & $-1,73 \pm 0,75$ & $-1,53 \pm 0,77$ & 0,15 \\
\hline \begin{tabular}{|l|} 
Menopoz yaşı \\
(medyan (min/max))
\end{tabular} & $48(39 / 55)$ & $48(40 / 55)$ & 0,09 \\
\hline $\begin{array}{l}\text { 25(OH) D vitamini } \\
\text { düzeyi (medyan } \\
(\min / \text { max)) }\end{array}$ & $\begin{array}{l}29,75 \\
(4,40 / 94,50)\end{array}$ & $\begin{array}{l}25,00 \\
(4,50 / 96,20)\end{array}$ & 0,10 \\
\hline
\end{tabular}

Tablo II. PMO’lu hastaların sigara ve alkol kullanımına ve annede kalça kırığı olup olmamasina göre dağılımı

\begin{tabular}{|l|l|l|}
\hline & $\begin{array}{c}\text { Grup 1 (kırıkı PMO) } \\
(\mathrm{n},(\%))\end{array}$ & $\begin{array}{c}\text { Grup 2 (kırıksız } \\
\text { PMO) (n, (\%)) }\end{array}$ \\
\hline $\begin{array}{l}\text { Sigara } \\
\text { Kullanan } \\
\text { Kullanmayan }\end{array}$ & $4(\% 8,0)$ & $5(\% 6,8)$ \\
\hline Alkol & $46(\% 92,0)$ & $69(\% 93,2)$ \\
Kullanan & $2(\% 4)$ & $2(\% 2,7)$ \\
Kullanmayan & $48(\% 96)$ & $72(\% 97,3)$ \\
\hline Annede kalça kıı̆ı̆ı & $3(\% 6,0)$ & $4(\% 5,4)$ \\
Var & $46(\% 94,0)$ & $70(\% 94,6)$ \\
Yok & \multicolumn{2}{|l}{} \\
\hline
\end{tabular}

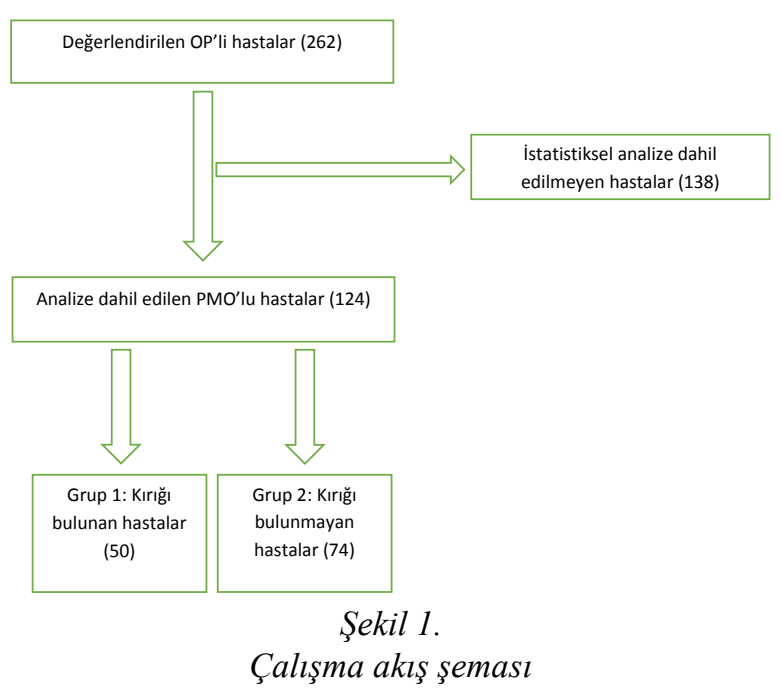

Tablo III. Kırığı olan PMO'lu hastaların kırık bulunan bölgelere göre dağılımı

\begin{tabular}{|l|l|}
\hline Kırık bölgeleri & $\mathbf{n , ~ ( \% )}$ \\
\hline Vertebral kııı & $\mathbf{3 3}(\% 66,0)$ \\
\hline Kalça kırı̆ı & $7(\% 14,0)$ \\
\hline Diğer alanlarda kırık & $10(\% 20,0)$ \\
\hline
\end{tabular}

\section{Tartışma ve Sonuç}

Vertebra kırığı riskiyle ilgili yayınlanmış epidemiyolojik veriler, kemik kütlesi azalmış ve 50 yaşın üzerindeki kadınlarda \%42 oranında kırık oluştuğunu göstermiştir ${ }^{12}$. Bizim çalışmamızda da literatüre benzer şekilde PMO'lu hastaların \%40,3'ünde osteoporotik kırık saptandi.

Yapılan çalışmalarda genel olarak ileri yaş ile osteoporotik kırık oluşumunun ilişkili olduğu saptanmıştır $^{13-15}$. Bizim çalışmamızda da literatürü destekler şekilde ileri yaş ile kırık oluşumu arasında istatistiksel olarak anlamlı ilişki saptandı.

Literatürde birçok çalışmada düşük $25(\mathrm{OH})$ vitamin D düzeyleri ile osteoporotik kırık oluşumunun ilişkili olduğu belirtilmektedir ${ }^{16-18}$. Bunun aksini gösteren çalışmalar da mevcuttur. Aul ve ark. sadece çok düşük 25(OH) vitamin D düzeylerini ( $<12 \mathrm{ng} / \mathrm{mL}$ ) el bileğinde artmış kırık riski ile ilişkili bulmuşlar, total osteoporotik kırık riski ile ilişkili bulmamışlardır ${ }^{19}$. Çalış ve ark. kırığı olan ve olmayan Parkinson hastalarında 25(OH) vitamin D düzeyleri ile osteoporotik vertebral kırık oluşumunun ilişkili olmadığını saptamışlardır ${ }^{20}$. Bizim çalışmamızda da $25(\mathrm{OH})$ vitamin D düzeyleri ile kırık oluşumu arasında anlamlı ilişki saptanmadi.

Düşük KMY değerleri ile osteoporotik kırık oluşumu arasında ilişki olduğu birçok çalışmada bildirilmiştir 21-23. Ancak bu ilişkinin aksini düşündüren çalışmalar da vardır. Literatürde KMY değerlerine göre osteopenili hastalarda da kırık geliştiğini destekleyen yayınlar 
mevcuttur ${ }^{24,25}$. Buradan hareketle çalışmalarda KMY'nin kırık olasılığını öngöremeyeceği, bu nedenle osteopenili hastalarda başka skorlamalara gereksinim olduğu belirtilmiştir ${ }^{25,26}$. Bizim çalışmamızda da KMY ile kırık oluşumu arasında ilişki saptanmadı. Femur total ve femur boyun $\mathrm{T}$ skorları kırık bulunan hastalarda daha düşük olsa da istatistiksel fark bulunamadı. Bizim çalışmamız KMY'nin kırık riskini öngörmede tek başına yeterli olmadığını ve hastaların risk faktörleriyle bütüncül olarak değerlendirilmesinin gerektiğini düşündürmektedir.

Düşük VKİ OP için bir risk faktörü olarak kabul edilmektedir ${ }^{27}$. Yapılan bir çalıșmada VKİ ile vertebra kırık oluşumu arasında anlamlı bir ilişki saptanmamış$\operatorname{tır}^{28}$. Başka bir çalışmada kadınlarda VKİ ve kırık riski arasındaki ilişkinin karmaşık olduğu ve farklı iskelet bölgeleri arasında değișiklik gösterdiği belirtilmiştir. Aynı çalışmada yüksek VKİ değerinin çoğu osteoporotik kırık bölgesi için koruyucu bir faktör olmaya devam ettiği belirtilmiştir ${ }^{29}$. Başka bir çalışmada kırığ bulunan PMO'lu kadınlarda VKİ $(31,68$ kg/m²) kırığ bulunmayan PMO'lu kadınlara göre $\left(30,04 \mathrm{~kg} / \mathrm{m}^{2}\right)$ daha yüksek bulunmuştur ${ }^{30}$. Bizim çalışmamızda kırık oluşumu ile VKİ arasında ilişki saptanmadı. Literatürde de genel olarak artmış VKİ'nin OP için koruyucu olduğu ama kırık riski ile ilişkisinin çelişkili bulunduğu düşünülürse, sonucumuzun literatür ile uyumlu olduğu söylenebilir.

Yapılan bir çalışmada erken menopoz yaşı, lomber KMY ile ilişkili bulunmamıș, fakat femur KMY'de azalma ile ilişkili bulunmuştur. Bu çalışmada hastalar kırık riski açısından değerlendirilmemiştir ${ }^{31}$. Başka bir çalışmada menopoz öncesi fertil dönem süresi ile osteoporotik kırık oluşumu arasında anlamlı ilişki saptanmamıștır². Anagnostis ve ark. erken menopoz yaşını yüksek kırık riski ile ilişkili bulmuşlardır ${ }^{32}$. Literatürde bu konuda kesin bilgiler olmamakla birlikte, erken menopoz yaşının kırık riskini arttırabileceği düşünülmektedir ${ }^{33}$. Bizim çalışmamızda ise literatürden farklı olarak menopoz yaşı ve kırık oluşumu arasında anlamlı ilişki saptanmadı.

Çalışmamızda ayrıca kırık risk faktörleri arasında gösterilen; annede kalça kırı̆̆ı öyküsü, sigara ve alkol kullanımı açısından iki grubun benzer şekilde dağıld1ğ1 belirlendi.

$\mathrm{Bu}$ çalışmanın zayıf yönleri arasından en önemlisi, hastaların geriye dönük olarak seçilmesidir. Buna bağlı olarak PMO'lu hastalarda kırık risk faktörlerinin tümü değerlendirilemedi. Ayrıca tek merkezli bir çalışma olup hasta sayısı sınırlı olduğundan, sonuçlarımız tüm PMO'lu hastaları temsil etmeyebilir.

Sonuç olarak, PMO’lu hastalarda kırık oluşumu en önemli morbidite ve mortalite nedenlerinin başında gelmektedir. Sonuçlar kırık oluşumunun tam anlamıyla öngörülmesinin zor olduğunu düşündürmekle birlikte, daha fazla sayıda veri ile yapılacak daha geniş hasta popülasyonunun tarandığı çalışmalara ihtiyaç olduğunu düşündürmektedir.

\section{Etik Kurul Onay Bilgisi:}

Onaylayan Kurul: Uludağ Üniversitesi Tıp Fakültesi Klinik

Araştırmalar Etik Kurulu.

Onay Tarihi: 20.01.2021

Karar No: 2021-2/19

\section{Araştırmacı Katkı Beyanı:}

Fikir ve tasarım: U.E.; Veri toplama ve işleme: U.E., J.I.; Analiz ve verilerin yorumlanması: U.E., J.İ.; Makalenin önemli bölümlerinin yazılması: U.E., J.İ.

\section{Destek ve Teşekkür Beyanı:}

Bu makalede yer alan çalışmalar için finansal destek alınmamıștır. Dr. Aytül Coşar Ertem ve Dr. Melike Şeyda Dağdelen'e istatistiksel analizler konusundaki desteklerinden dolayı teşekkür ederiz.

Çıkar Çatışması Beyanı:

Makale yazarlarının çıkar çatışması beyanı yoktur.

\section{Kaynaklar}

1. TFTR Derneği Osteoporoz Çalışma grubu. Postmenopozal Osteoporoz Tanı ve Tedavisinde Kanıta dayalı öneriler. TFTR Derneği Osteoporoz Çalışma grubu uzlaşı raporu 2017;1:13.

2. Odabaşı E, Turan M, Bilgiç S, Kutlu M. Osteoporotik Kırıkların Doğum Sayısı ve Fertil Dönem Süresi ile İlișkisi. TAF Prev Med Bull 2009;8(1):1-4.

3. Altunbayrak O. Pasif Sigara İçimi Postmenopozal Osteoporoz İçin Bir Risk Faktörü müdür? (Uzmanlık Tezi). İstanbul: İstanbul Eğitim ve Araştırma Hastanesi; 2008.

4. Bozbey I, Yalçın AP. Postmenopozal Osteoporoz Tedavisinde Stronsiyum Ranelat. Turk J Rheumatol 2009;24:149-55.

5. Kanis JA, Borgstrom F, Laet CD, et al. Assessment of fracture risk. Osteoporos Int. 2005;16:581-9.

6. Ross PD, Davis JW, Epstein RS, Wasnich RD. Pre-existing fractures and bone mass predict vertebral fracture incidence in women. Ann Intern Med. 1991;114(11):919-23.

7. Coughlan T, Dockery F. Osteoporosis and fracture risk in older people. Clin Med (Lond). 2014 Apr;14(2):187-91.

8. Hippisley-Cox J, Coupland C. Predicting risk of osteoporotic fracture in men and women in England and Wales: prospective derivation and validation of QFractureScores. BMJ. 2009 Nov 19;339:b4229.

9. Ogura-Tomamatsu H, Asano K, Tomamatsu K, et al. Predictors of osteoporosis and vertebral fractures in patients presenting with moderate-to-severe chronic obstructive lung disease. COPD. 2012 Aug;9(4):332-7.

10. Lai EL, Huang WN, Chen $\mathrm{HH}$, et al. Ten-year fracture risk by FRAX and osteoporotic fractures in patients with systemic autoimmune diseases. Lupus. 2019 Jul;28(8):945-53.

11. Crandall CJ, Larson J, LaCroix A, et al. Predicting Fracture Risk in Younger Postmenopausal Women: Comparison of the Garvan and FRAX Risk Calculators in the Women's Health Initiative Study. J Gen Intern Med. 2019 Feb;34(2):235-42.

12. Lindsay R, Pack S, Li Z. Longitudinal progression of fracture prevalence through a population of postmenopausal women with osteoporosis. Osteoporos Int. 2005 Mar;16(3):306-12.

13. Ma X, Xia H, Wang J, et al. Re-fracture and correlated risk factors in patients with osteoporotic vertebral fractures. J Bone Miner Metab. 2019 Jul;37(4):722-8. 


\section{Osteoporoz ve Kırık}

14. Yusuf AA, Hu Y, Chandler D, Crittenden DB, Barron RL. Predictors of imminent risk of fracture in Medicare-enrolled men and women. Arch Osteoporos. 2020 Aug 3;15(1):120.

15. Kanis JA, Cooper C, Rizzoli R, Reginster JY. European guidance for the diagnosis and management of osteoporosis in postmenopausal women. Osteoporos Int. 2019 Jan;30(1):3-44.

16. Çolak Y, Afzal S, Nordestgaard BG. 25-Hydroxyvitamin D and Risk of Osteoporotic Fractures: Mendelian Randomization Analysis in 2 Large Population-Based Cohorts. Clin Chem. 2020 May 1;66(5):676-85.

17. Looker AC. Serum 25-hydroxyvitamin D and risk of major osteoporotic fractures in older U.S. adults. J Bone Miner Res. 2013 May;28(5):997-1006.

18. Cauley JA, Parimi N, Ensrud KE, et al. Serum 25 hydroxyvitamin $\mathrm{D}$ and the risk of hip and nonspine fractures in older men. J Bone Miner Res. 2010 Mar;25(3):545-53.

19. Aul AJ, Dudenkov DV, Mara KC, et al. The relationship of 25hydroxyvitamin D values and risk of fracture: a populationbased retrospective cohort study. Osteoporos Int. 2020 Sep;31(9):1787-99.

20. Çalıs HT, Sütbeyaz ST, Sunkak S, et al. Osteoporotic Fractures and Posture Problem in Association with Vitamin D Level in Patients with Parkinson's Disease. Turk J Osteoporos 2017;23:16-20.

21. Trajanoska K, Morris JA, Oei L, et al. Assessment of the genetic and clinical determinants of fracture risk: genome wide association and mendelian randomisation study. BMJ. 2018 Aug 29;362:k3225.

22. Chalhoub D, Orwoll ES, Cawthon PM, et al. Areal and volumetric bone mineral density and risk of multiple types of fracture in older men. Bone. 2016 Nov;92:100-6.

23. Holmberg TF, Rubin KH, Brixen K, Tolstrup JS, Bech M. Fracture risk prediction using phalangeal bone mineral density or FRAX(®)?-A Danish cohort study on men and women. J Clin Densitom. Jan-Mar 2014;17(1):7-15.

24. Hillier TA, Cauley JA, Rizzo JH, et al. WHO absolute fracture risk models (FRAX): do clinical risk factors improve fracture prediction in older women without osteoporosis?. J Bone Miner Res. 2011 Aug;26(8):1774-82.

25. Schuit SCE, Klift MVD, Weel AEAM, et al. Fracture incidence and association with bone mineral density in elderly men and women: the Rotterdam Study. Bone. 2004 Jan;34(1):195-202.

26. Miller PD, Barlas S, Brenneman SK, et al. An approach to identifying osteopenic women at increased short-term risk of fracture. Arch Intern Med. 2004 May 24;164(10):1113-20.

27. Ravn P, Cizza G, Bjarnason NH, et al. Low body mass index is an important risk factor for low bone mass and increased bone loss in early postmenopausal women. $\mathrm{J}$ Bone Miner Res. 1999;14(9):1622-7.

28. Kaze AD, Rosen HN, Paik JM. A meta-analysis of the association between body mass index and risk of vertebral fracture. Osteoporos Int. 2018 Jan;29(1):31-9.

29. Johansson H, Kanis JA, Oden A, et al. A meta-analysis of the association of fracture risk and body mass index in women. $\mathrm{J}$ Bone Miner Res. 2014 Jan;29(1):223-33.

30. Poiana C, Carsote M, Radoi V, Mihai A, Capatina C. Prevalent osteoporotic fractures in 622 obese and non- obese menopausal women. J Med Life. 2015;8(4):462-6.

31. Onat ŞŞ, Delialioğlu SÜ, Özel S. The Relationship Between Osteoporotic Risk Factors and Bone Mineral Density. Turkish Journal of Osteoporosis 2013;19:74-80.

32. Anagnostis P, Siolos P, Gkekas NK, et al. Association between age at menopause and fracture risk: a systematic review and meta-analysis. Endocrine. 2019 Feb;63(2):213-24.

33. Lips P, Van Schoor NM. Quality of life in patients with osteoporosis. Osteoporos Int. 2005;16:447-55. 
